\title{
Remating effects on the genetic structure of female life histories in populations of Drosophila mojavensis
}

\author{
WILLIAM J. ETGES* \& WILLIAM B. HEED $\dagger$ \\ *Department of Biological Sciences, University of Arkansas, Fayetteville, Ark. 72701 and tDepartment of Ecology and \\ Evolutionary Biology, University of Arizona, Tucson, Ariz. 85721, U.S.A.
}

\begin{abstract}
A quantitative genetic analysis of nine adult fitness components was performed in two populations of cactophilic Drosophila mojavensis under natural conditions of fermenting cactus and ethanol vapour. Female progeny from 18 sires and 36 dams were treated to a range of six exposure periods to males to assess effects of remating frequency on female fitness. Lifetime fecundity increased with increasing male exposure, but longevity showed an intermediate optimum with temporary exposure to males of 2-4 days. Narrow-sense heritabilities were significant for egg production traits while broad-sense heritabilities were significant for longevity-related traits. Positive genetic correlations between components of fitness were expressed among functionally related traits, e.g. longevity was positively correlated with lifetime fecundity, the number of clutches laid, clutch size, and the number of eggs laid per day. Negative genetic correlations were detected between early and late life fecundity suggesting genetic tradeoffs among components of adult fitness.
\end{abstract}

Keywords: cactus, Drosophila, genetic correlation, heritability, life history, remating.

\section{Introduction}

The degree of parental investment in their genetic progeny is thought to result from a balance between future reproductive success and the immediate costs of parental care through investment of resources in current offspring. This classical tradeoff envisioned by Trivers (1972) has been perceived as a driving force in the evolution of plant and animal mating systems, particularly where sexual selection is involved (Parker, 1979). In many insect species, paternal contributions are essential elements of courtship behaviour and serve as nuptial gifts prior to copulation (Zeh \& Smith, 1985). These paternal contributions include the provision of food captured or glandular secretions provided by males (Thornhill \& Alcock, 1983). These contributions are presumably adaptive because they increase male mating success and may influence the fitness of his progeny. If females can choose males on the basis of their ability to provide, and such behaviour increases female fitness, sexual selection should reinforce natural selection and males that provide larger contributions will be favoured.

The paternal contribution of substances other than

*Correspondence. sperm used by females after copulation is well documented in 10 orders of insects (Thornhill \& Alcock, 1983; Boggs, 1990). Within the Drosophilidae, paternal investment may involve courtship feeding (Steele, 1986a, b), where males present a nuptial gift of regurgitated food to the female as part of courtship behaviour or the direct contribution of ejaculate compounds that females assimilate into somatic and reproductive tissues (Chen \& Buhler, 1970; Baumann, 1974; Markow \& Ankney, 1984; Scott, 1986; Bownes \& Partridge, 1987; Markow et al., 1990). Many compounds are present in the ejaculate of Drosophila males that can influence female receptivity to remating (Mane et al., 1983; Scott, 1986), increase oviposition rates (Chen, 1984), and may represent a source of energy in food-limited wild populations (Markow et al., 1990). The significance of any single kind of male contribution and its effects on female fitness and on the sire's progeny must therefore be evaluated in the context of the current mating system of a population.

Female cactophilic $D$. mojavensis remate every day or so in the laboratory (Markow, 1982) after a copulatory plug, formed from the insemination reaction from the last mating has cleared (Patterson, 1946, 1947). The insemination reaction in Drosophila species varies in intensity and duration, resulting from the reaction of 
vaginal secretions and non-sperm ejaculate compounds (Patterson, 1946; Grant, 1983). In D. mojavensis, ejaculate-derived amino acid-containing compounds are primarily retained in ovarian eggs and subsequently transferred from the female reproductive tract to somatic tissues throughout the body (Markow \& Ankney, 1984). Thus, male $D$. mojavensis have a direct effect on their progeny by contributing substances to eggs that they fertilize. Females may benefit directly by assimilating these compounds but it is unclear how these substances influence traits other than egg production, particularly in nature where adult nutrition has not been well studied (Etges \& Klassen, 1989).

The present study involves a systematic analysis of the causes of variation in nine components of adult fitness in female $D$. mojavensis. Effects of remating were investigated in a half-sib, full-sib experiment designed to distinguish between genetic and environmental influences on female fitness. Previous studies have shown remating influences on fitness components other than fecundity, such as longevity, in $D$. pseudoobscura (Turner \& Anderson, 1983), and D. melanogaster (Partridge et al., 1986, 1987), and courtship behaviour and female fertility (Gromko, 1987, 1989). Unfortunately little is known of the systematic effects of remating on the genetic basis of multiple components of female fitness. Furthermore, as the ecology of $D$. mojavensis is well known, all experiments were performed under environmental conditions designed to mimic nature, i.e. with fermenting cactus tissues and atmospheric volatiles as food (Etges \& Klassen, 1989). Here, we demonstrate strong influences of increasing exposure to males and nutrition on both female reproductive effort and the structure of life histories.

\section{Materials and methods}

Adult Drosophila mojavensis were aspirated from fermenting necrotic tissues, rots, of pitaya agria cactus, Stenocereus gummosus at two localities, Punta Prieta, Baja California Norte and Punta Onah, Sonora in March of 1989. Wild-caught adults were combined with all adults emerged from rots returned to the laboratory. The Baja stock was founded with 800 adults aspirated from rots plus 5042 adults emerged from 12 agria rots, and the mainland stock was founded with 210 adults from the field plus 196 adults emerged from three agria rots. Both populations were cultured in large numbers ( $>1000$ adults) in 8 -dram shell vials using banana-Karo-malt-brewer's yeast-agar food (Etges \& Heed, 1987) for 18 months prior to the start of the experiment. Vial-reared adults were then combined into six half-pint bottles per population and allowed to oviposit for 1 week to ensure optimal growth conditions for their offspring. All cultures were grown at room temperature $\left(\sim 22^{\circ} \mathrm{C}\right)$.

Virgin offspring from the bottle cultures were separated by sex using $\mathrm{CO}_{2}$ anaesthesia and aged for 6-7 days. Within each population, randomly selected sires were mated with three dams each for 1 week. The dams were then placed into separate vials and allowed to oviposit. Twelve female offspring from each of two dams were monitored for daily egg production under the following six treatments (two replicate females per treatment):

1 exposure to a male for $24 \mathrm{~h}$ after laying the first egg,

2 exposure to a male for $48 \mathrm{~h}$ after laying the first egg,

3 exposure to a male for $96 \mathrm{~h}$ after laying the first egg,

4 exposure to one male until death,

5 exposure to two males until death, and

6 exposure to four males until death.

We assumed that increasing exposure to males is correlated with an increased frequency of remating, and hence higher transmission rates of sperm and ejaculate compounds. Females were aged for 2-3 days on organ pipe food (see below) that was brought to 5 per cent concentration and supplemented with killed yeast before mating because sexual maturity is not attained until 3-5 days (Etges \& Klassen, 1989). All males were from outbred stocks of each population.

Each of the 24 female offspring per sire in the six treatments were housed in empty 1-dram shell vials glued into each well of a disposable 24-well microtitre plate. The top of each vial was fitted with a plastic cap which had been cored and sealed with nylon netting. The mesh was large enough to allow the females to oviposit through it but small enough that the flies could not escape. Each day, all sets of vials were inverted onto flats of fermenting organ pipe cactus from 18.00 until 09.00 hours the following morning in order that all females could feed and oviposit on the cactus medium. From 09.00 until 18.00 hours, all vial sets were placed into sealed desiccators containing 1 litre of 4 per cent ethanol $(\mathrm{v} / \mathrm{v})$ made fresh every other day (Etges \& Klassen, 1989). All flies were housed in an incubator with a $14: 10 \mathrm{LD}$ photoperiod set at $27^{\circ} \mathrm{C}$ during the day and $17^{\circ} \mathrm{C}$ at night while exposed to cactus and ethanol vapour. All females were checked daily for mortality and males were replaced if dead. All eggs laid were counted each day and transferred to laboratory food in shell vials. All pupae and eclosing adults were counted from each vial.

The organ pipe food was prepared by blending fresh organ pipe cactus with 2 per cent agar-deionized water until the mixture was pourable, autoclaved, and poured into rectangular baking pans. After cooling, these flats were frozen until needed. Once thawed, the cactus tissue was inoculated with a suspension of seven yeast 
species common to agria and organ pipe rots in nature (Starmer, 1982; Fogleman \& Starmer, 1985); Pichia cactophila, $P$. mexicana, $P$. amethionina var. amethionina, Cryptococcus cereanus, Candida valida, $C$. ingens, and Torulopsis sonorensis and incubated at $25^{\circ} \mathrm{C}$ for at least 2 days. Abundant yeast growth was evident on all flats used.

\section{Statistical analysis}

The dataset was composed of the following variables recorded for each female: longevity in days, lifetime fecundity, mean number of eggs laid per day, number of times eggs were laid (number of clutches), mean clutch size, mean clutch viability (mean number of adults eclosed/number of eggs laid), age when the largest clutch was produced, mean age at oviposition, and the coefficient of variation of the age when a female laid eggs, an estimate of the variance in reproductive effort throughout each female's lifetime.

The final dataset was mildly unbalanced due to unavailability of the required 12 female offspring for each dam and to escaping flies. The total sample size was 406 females from 18 sires and 36 dams. Viability data were arcsin transformed and clutch size data were $\log$ transformed. Analyses of variance and correlation analyses were performed using SAS procedures (SAS Institute, Inc., 1985). The GLM and NESTED procedures were used to estimate significance levels and variance components for each variable using the model:

$Y_{\mathrm{ijklm}}=\mu+N_{\mathrm{i}}+P_{\mathrm{j}}+S_{\mathrm{k}}+D_{\mathrm{l}}+I_{\mathrm{nxp}}+E_{\mathrm{ijklm}}$

where $\mu$ is the grand mean, $N_{\mathrm{i}}$ is the treatment effect of exposure to males, $P_{\mathrm{j}}$ is the effect of population, $S_{\mathrm{k}}$ is the effect of sire nested within population, $D_{1}$ is the effect of dams nested within sires, $I_{\text {nxp }}$ is the interaction between male exposure and population, and $E_{\mathrm{ijklm}}$ is the within full-sib family error. All levels were considered random effects except for exposure time to males and the interaction, $N_{\mathrm{i}}$ and $I_{\text {nxp }}$. Detection of sire $\mathrm{X}$ male exposure treatment interactions in the ANOVA was not possible due to the extensive memory requirement of this model.

Heritabilities were calculated for all variables with variance components from PROC NESTED, where

$h_{\mathrm{s}}^{2}=\frac{4 \sigma_{\mathrm{s}}^{2}}{\sigma_{\mathrm{s}}^{2}+\sigma_{\mathrm{d}}^{2}+\sigma_{\mathrm{w}}^{2}}$

and

$$
h_{\mathrm{d}}^{2}=\frac{4 \sigma_{\mathrm{d}}^{2}}{\sigma_{\mathrm{s}}^{2}+\sigma_{\mathrm{d}}^{2}+\sigma_{\mathrm{w}}^{2}}
$$

$h^{2}{ }_{\mathrm{s}}$ is the narrow-sense heritability based upon the sire component of variance $\sigma^{2}$, where $h^{2}$ is the broadsense heritability (Falconer, 1981) that includes four times the maternal effects, dominance variance, etc. in the numerator (Becker, 1984). $\sigma^{2}{ }_{d}$ is the dam (full-sib) component of variance and $\sigma^{2}{ }_{w}$ is the component of variance among progeny, within dams

$\sigma^{2}{ }_{w}=\sigma^{2}{ }_{\mathrm{r}}-\left(3 \sigma^{2}{ }_{\mathrm{d}}-\sigma^{2}{ }_{\mathrm{s}}\right)$

where $\sigma_{\mathrm{r}}^{2}$ is the residual variance.

Genetic and phenotypic correlations were calculated between all variables. Genetic correlations were calculated in three ways: parametric (Pearson productmoment) and non-parametric (Spearman rank-sum) correlations were calculated using sire means, both of which may underestimate the true genetic correlation (Via, 1984) but allow straightforward significance testing, the additive genetic correlations using the sire variances and covariances from procedure NESTED.

\section{Effects of dietary protein on egg production}

Variation in dietary protein was assayed by manipulating the amount of commercially available brewer's yeast in laboratory food (contents listed above) because components of the cactus diet could not be manipulated. A majority of dietary protein in laboratory food is contained in yeast $(4.62$ per cent $\mathrm{w} / \mathrm{v})$ and malted barley $(4.8$ per cent $\mathrm{v} / \mathrm{v})$ : the yeast concentrations used as treatments in one-way ANOVA corresponded to $2.33,12.07,17.73$ and 24.22 per cent total protein $(\mathrm{w} / \mathrm{v})$ determined by a modified Kjeldahl method. Females eclosing directly from agria rots from Punta Prieta were used. Each female was exposed to two mature males for life in 8-dram shell vials at room temperature and ambient lighting. Twenty-five females per food treatment were started when the females were 2-3 days old, and transferred daily to fresh food. All eggs were counted daily. Towards the end of the experiment, selected females from each treatment were measured for thorax size, ovariole number, and egg size. Egg volume was approximated as the volume of a prolate spheroid, i.e. volume $=(1 / 6) \pi w^{2} l$, where $w=$ egg width and $l=$ egg length (Atkinson, 1979; Montague, et al., 1981).

Lifetime fecundities were also subjected to time series, or spectral analyses (Bloomfield, 1976) using a finite Fourier transform procedure form ILS (Interactive Laboratory System V. 6.1, 1989). This procedure decomposes discrete time-sequence data into a set of frequency components, here employed to detect cycles in the pattern of oviposition in female $D$. mojavensis. 


\section{Results}

Of 406 females studied in the main experiment, 102 never laid an egg. Such behaviour is consistent with earlier studies of fecundity of $D$. mojavensis in cactusethanol vapour environments (Etges \& Klassen, 1989) and on laboratory food (Markow et al., 1990). Maximum lifetime fecundity was 440 eggs, with a mean of 54 eggs for all females. The average clutch size was 23.3 eggs while the median number of clutches laid per female was two, i.e. most females only laid eggs twice in their lifetime. The average longevity was 21.5 days, and one female lived 55 days.

\section{Remating effects on life history traits}

Variation in the exposure of females to males had large effects on female longevity, lifetime fecundity, number of clutches laid, average number of eggs laid per day, and the degree to which reproduction was distributed throughout adult life, the coefficient of variation $(\mathrm{CV})$ of the age of oviposition (Table 1). In the original experimental design, exposure to males for 24,48 , and $96 \mathrm{~h}$ was intended to begin when the females were sexually mature, at age 2-4 days (Etges \& Klassen, 1989). Once the experiment was underway, it was clear that these exposure periods would have to be increased

Table 1 Nested ANOVA for the nine life-history variables measured in this experiment. Characterization of the variables is given in the text

\begin{tabular}{|c|c|c|c|c|c|c|c|c|c|}
\hline \multirow[b]{2}{*}{ Source } & \multicolumn{3}{|c|}{ Longevity } & \multicolumn{3}{|c|}{ Lifetime fecundity } & \multicolumn{3}{|c|}{ Average number eggs laid/day } \\
\hline & d.f. & Type IV SS & $F$ & d.f. & Type IV SS & $F$ & d.f. & Type IV SS & $F$ \\
\hline Model & 45 & 11002.30 & $3.01^{* * * * *}$ & 45 & 503526.33 & $3.38^{* * * * *}$ & 45 & 864.67 & $4.72^{* * * *}$ \\
\hline Sperm $\ddagger$ & 5 & 2681.61 & $6.59 * * * *$ & 5 & 61069.48 & $3.69^{* * *}$ & 5 & 165.71 & $8.14^{* * * *}$ \\
\hline Population & 1 & 201.41 & $0.94 \mathrm{~ns}$ & 1 & 2.58 & $0.00 \mathrm{~ns}$ & 1 & 0.00 & $0.00 \mathrm{~ns}$ \\
\hline Sire (pop.)§ & 16 & 3420.27 & $1.72 \mathrm{~ns}$ & 16 & 309744.78 & $3.99^{* * *}$ & 16 & 509.63 & $4.56^{* * *}$ \\
\hline Dam (pop. sire) $\pi$ & 18 & 2242.32 & $1.53^{*}$ & 18 & 87251.04 & $1.46 \mathrm{~ns}$ & 18 & 125.65 & $1.71^{* *}$ \\
\hline Sperm × pop. & 5 & 2062.97 & $5.07^{* * *}$ & 5 & 26658.05 & $1.61 \mathrm{~ns}$ & 5 & 30.09 & $1.48 \mathrm{~ns}$ \\
\hline Error & 360 & 29287.04 & & 360 & 1192164.69 & & 360 & 1466.19 & \\
\hline
\end{tabular}

Average age of oviposition $\quad \mathrm{CV}$ (Age of oviposition)

Age at peak lay

\begin{tabular}{|c|c|c|c|c|c|c|c|c|c|}
\hline Model & 45 & 2104.52 & $2.21^{* * * * *}$ & 45 & 19175.08 & $1.89^{* * *}$ & 45 & 2740.97 & $2.24^{* * * *}$ \\
\hline Sperm & 5 & 192.03 & $1.82 \mathrm{~ns}$ & 5 & 4587.37 & $4.07^{* * *}$ & 5 & 241.99 & $1.78 \mathrm{~ns}$ \\
\hline Population & 1 & 92.60 & $1.61 \mathrm{~ns}$ & 1 & 979.36 & $2.11 \mathrm{~ns}$ & 1 & 45.66 & $0.62 \mathrm{~ns}$ \\
\hline Sire (pop.) & 16 & 923.10 & $1.23 \mathrm{~ns}$ & 16 & 7410.43 & $1.52 \mathrm{~ns}$ & 16 & 1187.13 & $1.21 \mathrm{~ns}$ \\
\hline Dam (pop. sire) & 18 & 846.21 & $2.22^{* * *}$ & 18 & 5467.73 & $1.35 \mathrm{~ns}$ & 18 & 1103.63 & $2.26^{* * *}$ \\
\hline Sperm $\times$ pop. & 5 & 333.07 & $3.15^{* *}$ & 5 & 1074.62 & $0.95 \mathrm{~ns}$ & 5 & 168.03 & $1.24 \mathrm{~ns}$ \\
\hline Error & 258 & 5451.76 & & 258 & 58171.19 & & 258 & 7003.76 & \\
\hline & \multicolumn{3}{|c|}{$\log _{10}$ (clutch size) } & \multicolumn{2}{|c|}{ Number clutches laid } & \multicolumn{4}{|c|}{ Clutch viability } \\
\hline Model & 45 & 8.22 & $1.74^{* * *}$ & 45 & 1028.69 & $3.09^{* * * *}$ & 45 & 7.52 & $1.20 \mathrm{~ns}$ \\
\hline Sperm & 5 & 0.43 & $0.82 \mathrm{~ns}$ & 5 & 138.68 & $3.75^{* * *}$ & 5 & 0.19 & $0.27 \mathrm{~ns}$ \\
\hline Population & 1 & 0.01 & $0.03 \mathrm{~ns}$ & 1 & 0.14 & $0.02 \mathrm{~ns}$ & 1 & 0.22 & $0.90 \mathrm{~ns}$ \\
\hline Sire (pop.) & 16 & 4.48 & $1.93^{*}$ & 16 & 623.27 & $3.69^{* * *}$ & 16 & 3.91 & $1.46 \mathrm{~ns}$ \\
\hline Dam (pop. sire) & 18 & 2.60 & $1.38 \mathrm{~ns}$ & 18 & 190.13 & $1.43 \mathrm{~ns}$ & 18 & 3.00 & $1.20 \mathrm{~ns}$ \\
\hline Sperm $\times$ pop. & 5 & 0.58 & $1.11 \mathrm{~ns}$ & 5 & 29.86 & $0.81 \mathrm{~ns}$ & 5 & 0.18 & $0.26 \mathrm{~ns}$ \\
\hline Error & 258 & 27.09 & & 360 & 1695691.02 & & 258 & 35.89 & \\
\hline
\end{tabular}

${ }^{*} 0.1<P<0.05,{ }^{* *} P<0.05,{ }^{* * *} P<0.005,{ }^{* * * *} P<0.0001$, ns $=$ not significant.

$\ddagger$ Sperm refers to the six treatments of female exposure to males.

$\S$ Sires nested within population.

IDams nested within sires nested within population. 
because most of the females had not oviposited at the end of these exposure periods. Thus, the exposure times used were the periods males were kept with females after the first egg was laid.

Table 2 Multiple comparisons tests for mean longevity and fecundity arranged by the exposure period to males (sperm). Categories under sperm indicate increasing exposure levels to males and are defined in Fig. 1. Means with the same letter superscript are not significantly different by Duncan's multiple range test $(P<0.05)$

\begin{tabular}{llllll}
\hline & $\begin{array}{l}\text { Mean } \\
\text { longevity }\end{array}$ & Sperm & Sperm & $\begin{array}{l}\text { Mean } \\
\text { fecundity }\end{array}$ & $n$ \\
\hline 70 & $25.114^{\mathrm{a}}$ & 2 & 5 & $70.090^{\mathrm{a}}$ & 67 \\
68 & $24.412^{\mathrm{ab}}$ & 3 & 4 & $68.761^{\mathrm{a}}$ & 67 \\
67 & $21.418^{\mathrm{bc}}$ & 4 & 6 & $56.359^{\mathrm{ab}}$ & 64 \\
70 & $21.157^{\mathrm{c}}$ & 1 & 3 & $48.765^{\mathrm{abc}}$ & 68 \\
67 & $19.493^{\mathrm{cd}}$ & 5 & 2 & $45.600^{\mathrm{bc}}$ & 70 \\
64 & $17.141^{\mathrm{d}}$ & 6 & 1 & $33.100^{\mathrm{c}}$ & 70 \\
\hline
\end{tabular}

The average longevity of each population responded differently to exposure time to males causing a significant interaction between exposure time and population (Table 1). Even so, comparisons among the six treatment groups revealed significant trends (Table 2). Because standard errors of the treatment means were large, $t$-tests were used to determine which groups were significantly different from others. Longevity increased with increased exposure to males from $24 \mathrm{~h}$ to the 48- and 96-h treatments combined $t=-2.01$, $P<0.05)$, and then decreased significantly from the two males for life to four males for life treatment $\langle t=2.04, P<0.05$, Fig. 1). Mean longevity in the highest exposure treatment was lower than that of the $24 \mathrm{~h}$ exposure treatment $(t=2.98, P<0.01)$, but not the other lifetime exposure treatments $(t=-0.16$ and 1.08 , respectively, both $P>0.2$ ). Thus, variation in longevity could not have resulted solely from mating with more males and laying more eggs (Table 2).

The effects of remating were similar among popula-
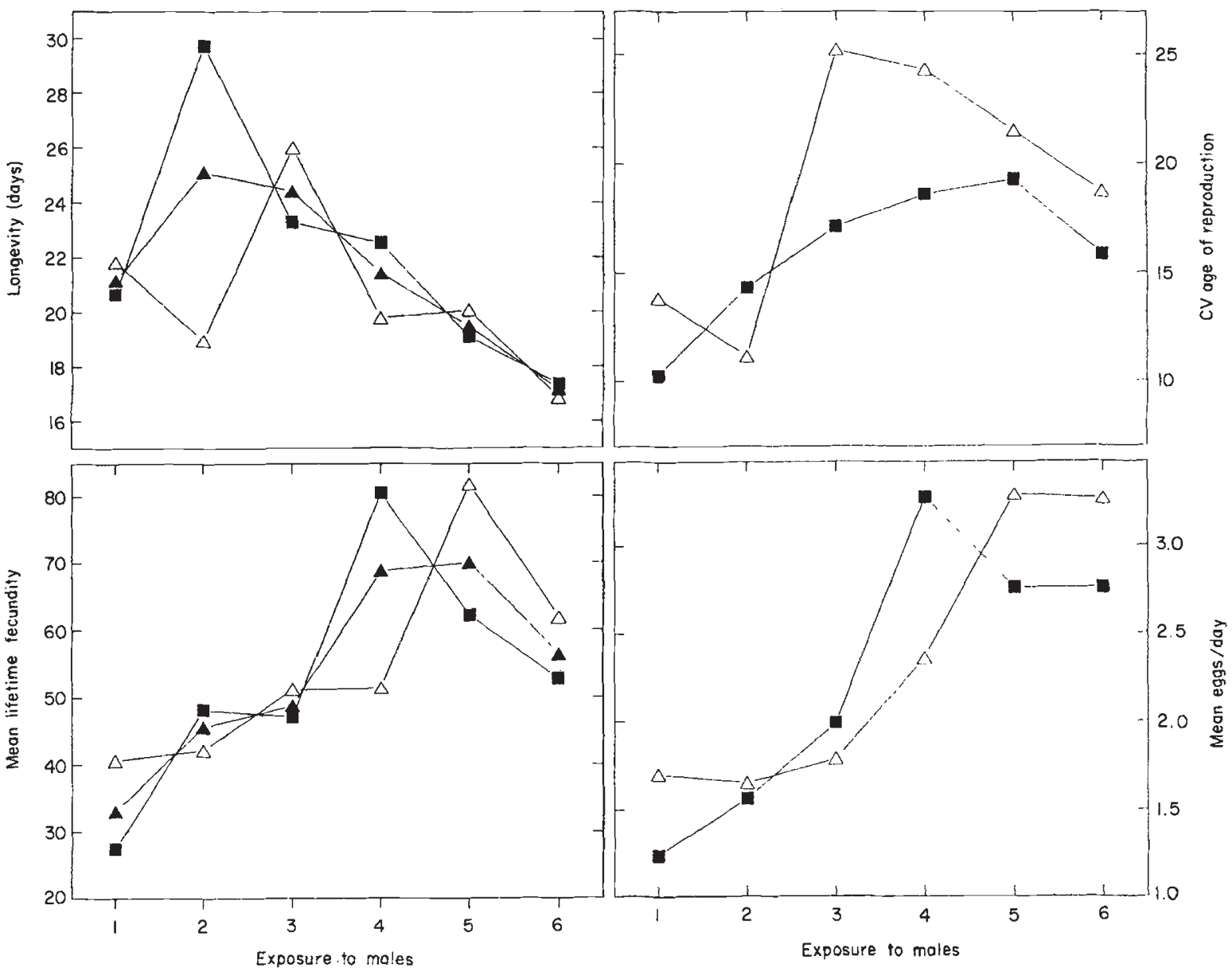

Fig. 1 Plots of responses in population-specific female longevity, lifetime fecundity, average number of eggs laid per day, and variation in age at reproduction to the six exposure levels to males are shown, where $1=$ exposure for $24 \mathrm{~h}, 2=$ exposure for $48 \mathrm{~h}$, etc. Population means are also plotted for longevity and lifetime fecundity to show overall trends more clearly. Confidence

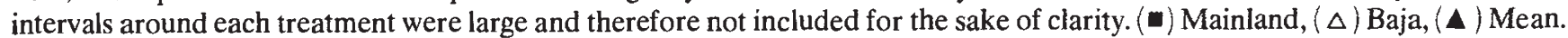


tions for lifetime fecundity, the $C V$ of age at reproduction, the average number of eggs laid per day (Fig. 1). The average number of eggs laid per day was included solely to correct for intrinsic differences in female longevity and therefore estimated egg production independently of lifespan. This variable exhibited an asymptote at about three eggs per day in the lifetime exposure to males treatments (Fig. 1). Fecundity significantly increased from the three non-lifetime to three lifetime exposure treatments combined $(t=-2.60$, $P<0.01$, Fig. 2, Table 2). Mean fecundity in the highest exposure treatment was not significantly different from the other lifetime exposure treatments $(t=1.02$, $P>0.2$ ), but the $24-\mathrm{h}$ exposure treatment resulted in significantly lower lifetime fecundity than any of the lifetime exposure treatments $(t=-2.75, P<0.01)$. Increased exposure to males also caused increases in the variance of the age of oviposition (Fig. 1) but, as with the other egg-laying variables, showed evidence of a decrease in the lifetime exposure classes. None of these traits differed among populations in contrast with earlier studies documenting genetic differences among mainland and Baja populations in life-history charac- ters (Etges \& Heed, 1987; Etges, 1990), including lifetime fecundity (Etges \& Klassen, 1989).

\section{Remating effects on clutch viability}

Clutch viability was not influenced by any level in the ANOva (Table 1). As this trait reflects the confounding of egg hatchability and egg-to-adult survivorship on laboratory food, a post hoc control experiment was performed to measure larval viability. First instar larvae from both populations were counted out into five replicate vials each at densities of $1,3,5,10,15$, 25,35 , and 50 per vial, and the total number of pupae/ adults was counted. The average viability for the mainland population across densities was 0.83 (s.d. $=0.06$ ) and that for the Baja population was 0.69 (s.d. $=0.13)$. These means were not significantly different (paired $t$-test, $P>0.05$ ).

The relationship between exposure to males and the number of unfertilized eggs laid was determined because there were a considerable number of clutches laid that produced no larvae. In the wild, this would incur a considerable cost in fitness to those females that

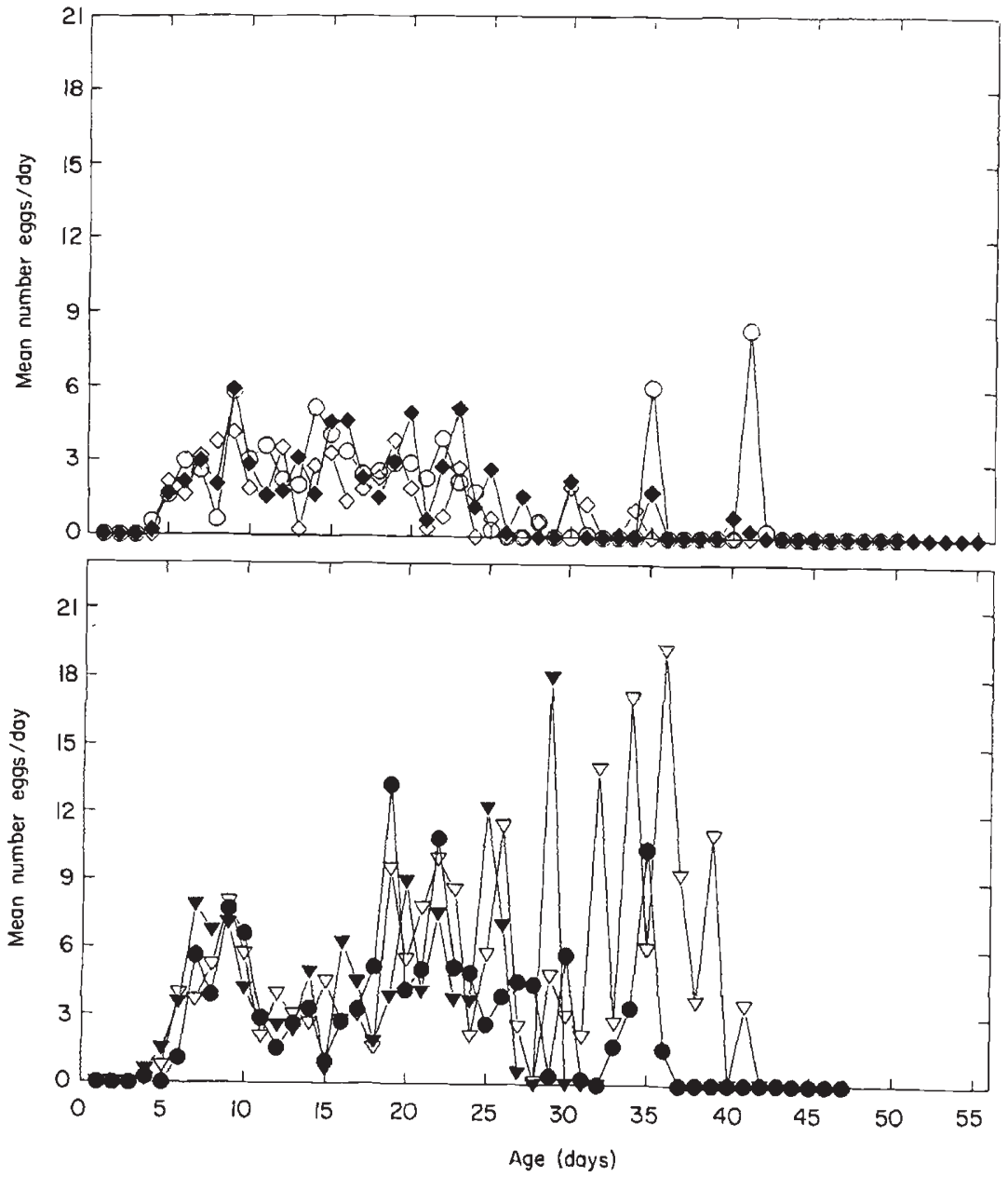

Fig. 2 Lifetime egg production in the short versus lifetime exposure to male treatments. Note the increase in late life reproduction in the lifetime exposure group. $(\diamond) 24 \mathrm{~h},(\bullet) 48 \mathrm{~h},(0) 96 \mathrm{~h} .(\bullet) 1$ 0 for life, $(\nabla) 20^{\circ} 0^{\circ}$ for life, $(\nabla) 40^{\circ} 0^{\circ}$ for life. 
cannot fertilize the clutches of eggs that they are maturing. These eggs appear clear with white or yellow patches of yolk throughout the cytoplasm, characteristic of unfertilized embryos (Sonnenblick, 1950). The viability of any clutch less than 0.50 is likely to be due to the production of unfertilized eggs rather than low egg-to-adult viability, given the results of the above control experiment. A frequency distribution of clutch viabilities, $v_{\mathrm{i}}$, was formed with intervals of 0.05 starting from zero and ending with $v_{\mathrm{i}} \geq 0.50$. There was clearly a bimodal distribution of clutches with the majority of observations in the 0 and $0-0.05$ clutch viability classes and those in the $\geq 0.50$ class (Fig. 3 ).

Clutch viabilities were reclassified into one of three categories; $0.0 \leq v_{\mathrm{i}} \leq 0.05,0.05<v_{\mathrm{i}} \leq 0.50$, and $v_{\mathrm{i}}>0.50$ and analysis of variance was performed for each category using the same nested model as in Table 1 . No significant differences among male exposure classes were detected in the $0.0 \leq v_{\mathrm{i}} \leq 0.05$ class, indicating that females occasionally lay completely or largely unfertilized clutches irrespective of the number of males present. However, male exposure significantly affected clutch viability in the latter two categories $(F=2.95, P=0.013$, and $F=4.87, P=0.0003$, respectively). Clutch viability was highest in the three lifetime exposure classes (Fig. 3). The same trend was apparent in the $0.05<v_{\mathrm{i}} \leq 0.50$ viability class, except the mean for the highest exposure class, four males for life, was not significantly different from the means of the three low-exposure treatments (Fig. 3). These results indicate that the number of males, and therefore the number of potential matings to which female $D$. mojavensis have access, influenced their ability to fertilize mature eggs. The decrease in clutch viability in the highest exposure class accompanied decreases in lifetime fecundity (Fig. 1) which suggests that excess male exposure is detrimental to female reproductive success.

\section{Effects of dietary protein on egg production}

Lifetime fecundity increased nearly 21 -fold from the lowest to highest protein level (Fig. 4). Protein concentration increased lifetime fecundity $(F=14.3$, $P<0.0001)$, eggs laid per day $(F=15.72, P<0.0001)$, ovariole numbers $(F=4.54, P<0.0005)$, and mean egg volume per female $(F=3.14, P<0.05)$. A total of 43 females from the four treatments were dissected for ovariole number, of which 30 contained mature eggs that could be measured. Food containing 17.7 per cent protein caused females to produce an average of four

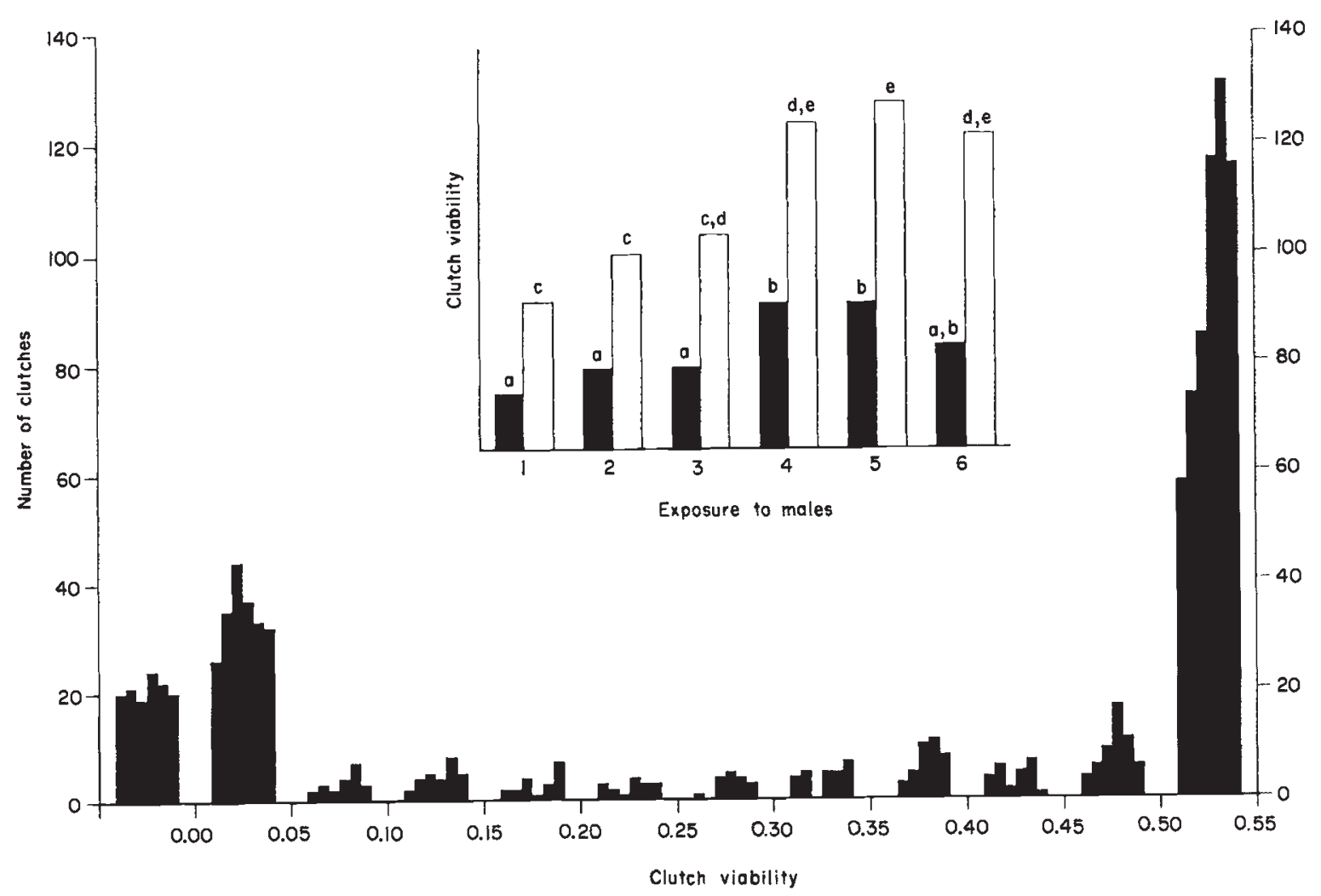

Fig. 3 The number of observed clutches is plotted for the six male exposure classes in each viability frequency class from 0 to 0.50 . Bars in the histograms in each frequency class represent the male exposure classes from 1 to 6 as in Fig. 1.

Inset: clutch viability classes $0.05<v_{i} \leq 0.5$ combined $(\square)$ and the $>0.5$ class $(\square)$ plotted by male exposure treatment. Bars sharing the same letter are not significantly different by Duncan's multiple range test $(P<0.05)$. See text for details. 


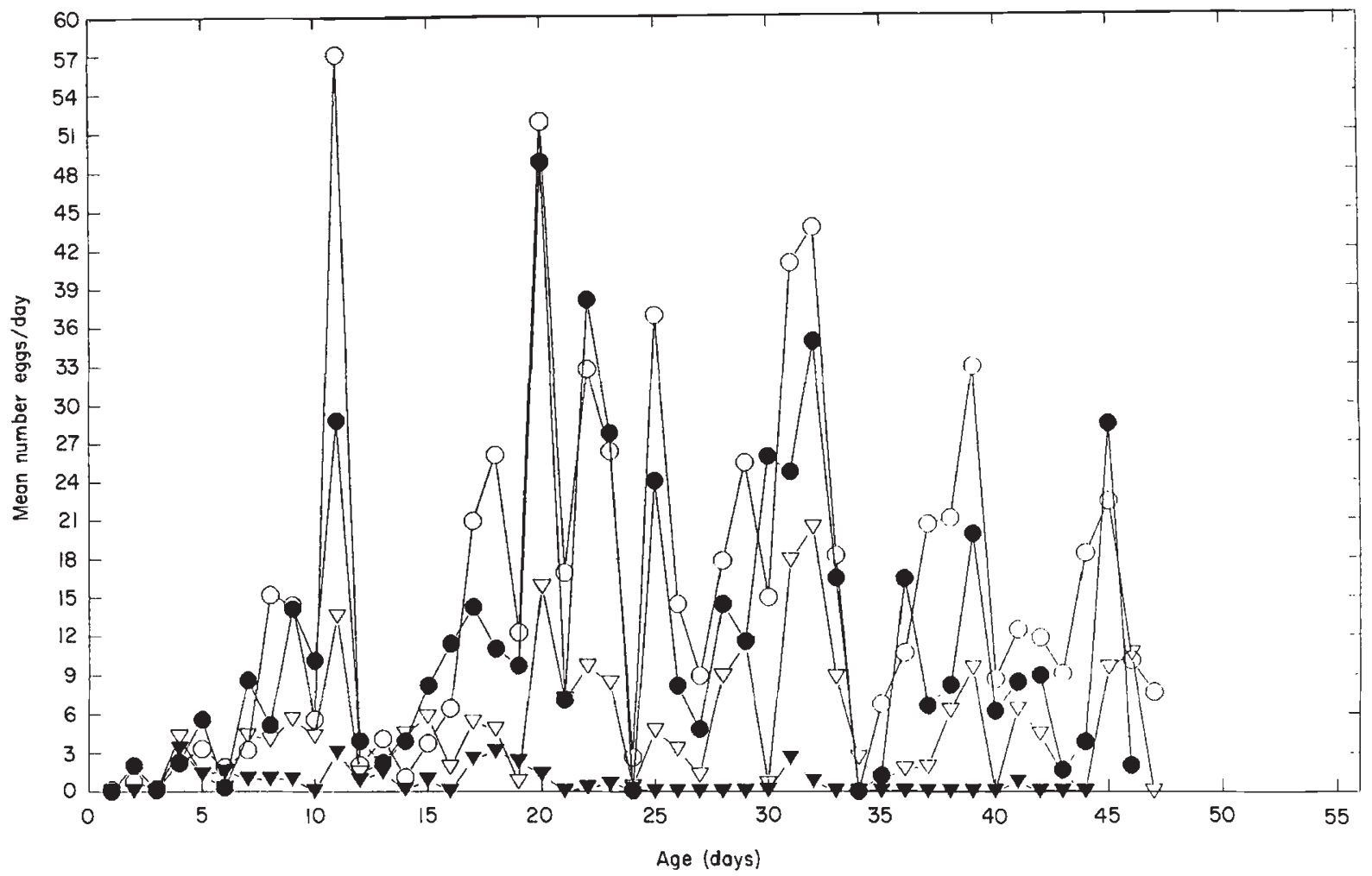

Fig. 4 Lifetime egg production from each of the four food treatments used to assay the effects of varying dietary protein on egg production. The amount of nutritional yeast indicated corresponds to the four concentrations of protein described in the text. The $1 \times$ treatment corresponds to the customary amount of yeast used for day-to-day fly culturing. $(\nabla)$ No yeast, $(\nabla) 1 \times$ yeast, $(\bullet) 2 \times$ yeast, $(0) 4 \times$ yeast.

eggs laid per day, comparable to the highest egg-laying rates in the remating experiment. A doubling of protein content from 12.07 to 24.22 per cent caused ovariole numbers to increase from a mean of 23.5 per female to 26.6 per female $(t=2.31, P<0.05$, d.f. $=25)$. Thorax sizes of these dissected females were not significantly different among treatments (thorax size and ovariole number in $D$. mojavensis are positively correlated [W. B. Heed, unpublished data cited in Etges, (1990)], so random differences in body size cannot explain the response to increased protein. Therefore, adult nutrition influenced ovariole numbers.

\section{Oviposition cycles}

Patterns of oviposition in both egg-laying experiments differed with a marked cycle of about 10 days on cactus and no detectable cycles in the higher protein treatments (Figs. 5 and 6). As the latter experiment was performed under uncontrolled photoperiodic conditions, it is possible that expression of ovarian cycling is affected by photoperiod length. However, females in the 'no yeast' treatment exhibited a number of cycles although none were as striking as in the remating experiment. Decreases in cycling with increases in protein intake suggest strong nutritional influences on the rate of synchronous egg maturation, i.e. the more eggs produced, the more asynchronously eggs were laid.

\section{Genetic basis for adult life-history components}

As there were no population differences in any of the ANOVA (Table 1), all data were combined for estimation of variance components. Significant sire effects were detected for the three egg production traits; lifetime fecundity, number of clutches laid, and the average number of eggs laid per day. Thus, additive genetic variance for egg production persists in these populations. Heritabilities were relatively high for these three traits, greater than 0.7 (Table 3). Significant dam effects indicated non-additive and/or maternal effects for longevity, average number of eggs laid per day, the average age of oviposition, and age at peak lay. As these are all age-related traits, these dam effects may stem from similar causes influencing longevity. The data across male exposure treatments were pooled in this analysis, therefore the results of all genetic analyses include this spectrum of remating effects.

Genetic and phenotypic correlations among all traits 


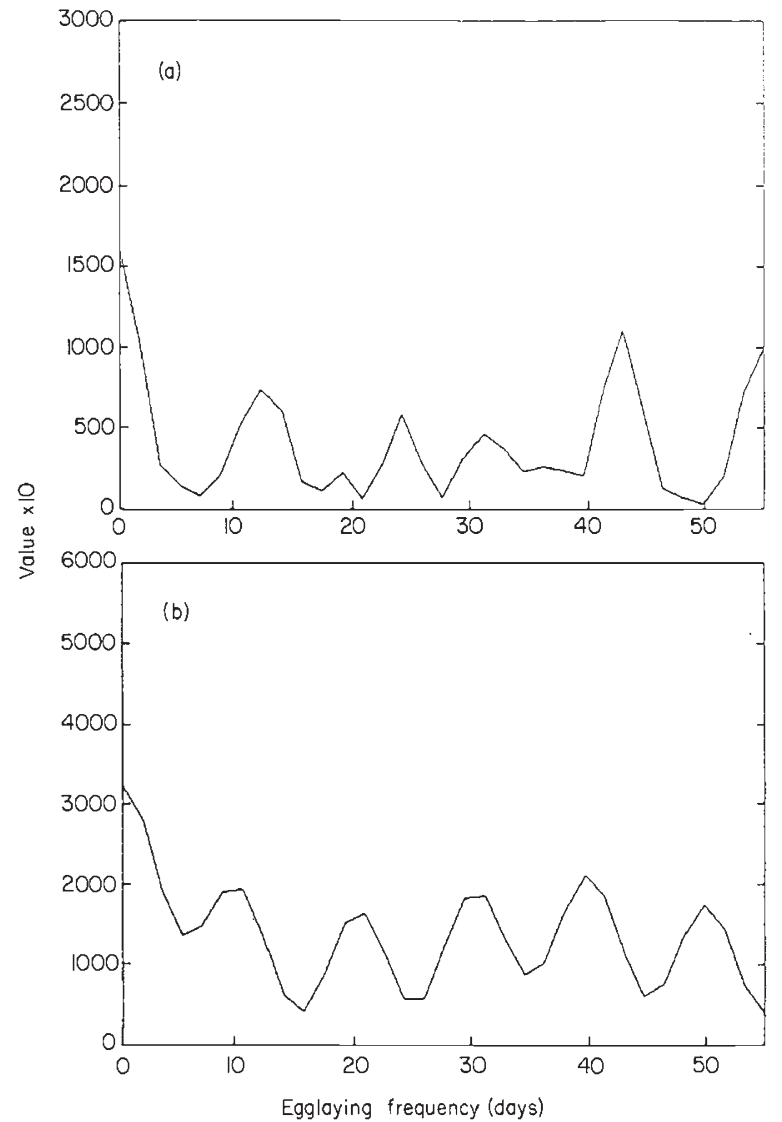

Fig. 5 Power spectra of ovipositon patterns in (a) mainland and (b) Baja females. Peaks in the curves represent frequencies in days when fecundities increased. The $y$ axes are in arbitrary units of the power density spectrum.

are shown in Table 4. No differences were observed between parametric and non-parametric correlation results, so only parametric results are shown. Phenotypic correlations were calculated with the male exposure treatment means for both populations $(n=12)$ and using all experimental females $(n=406)$. All the significant phenotypic correlations among traits related to productivity were positive, as expected. Of those based on the six treatment means (below the diagonal in Table 4), correlations between longevity and fecundity, longevity and number of clutches laid, and longevity and number of eggs laid per day were negative but not significant. These correlations indicate possible tradeoffs between longevity and reproductive effort driven by mating frequency, but because the responses to male exposure treatments were not linear (Fig. 1) and the number of means was small, it is not surprising that the correlations were not statistically significant. The correlation between longevity and eggs laid per day, $r=-0.483(P=0.111)$, was the strongest indication that collapsing the dataset to just 12 classes reduced the power of this test.
Genetic correlations were calculated with the sire means of each trait (Via, 1984) and with sire variance components from procedure NESTED (SAS Institute, 1985). Correlation analysis of all traits except longevity, fecundity, number of clutches laid per day was based on a reduced and quite unbalanced dataset due to the 102 females that laid no eggs. This made significance testing of additive genetic correlations difficult because of their well known lack of statistical power with unbalanced data. Overall, these techniques gave consistent results, and in many cases were comparable with the phenotypic correlations (Table 4). Across all male exposure treatments, longevity was positively correlated with lifetime fecundity, number of clutches laid, clutch size, and the number of eggs laid per day, indicating that strong positive genetic correlations between components of fitness were expressed among functionally related traits. Furthermore, longevity and age at peak reproduction were negatively correlated providing additional evidence for positive pleiotropy where concentrating reproductive effort early in life is associated with increased longevity (Scheiner et al., 1989). However, longer-lived females laid more eggs, but those laid later in life displayed lower hatching rates as suggested by the negative correlation between longevity and clutch viability. We caution against interpreting this latter correlation as a tradeoff in lifetime reproductive effort where eggs laid later in life suffered decreased hatchability because of the inability to show that this correlation is different from zero.

Thus, neither lifetime fecundity nor number of eggs laid per day were reliable indicators of female fitness because of the negative genetic correlations with clutch viability. However, females that concentrated oviposition into fewer, smaller clutches produced more viable offspring, as indicated by the negative correlations between clutch viability, coefficient of variation of the age of oviposition, and clutch size. The average age at reproduction, calculated by averaging age in days when clutches were produced, was negatively correlated with eggs laid per day. Age when the largest clutch was produced was also negatively correlated with the number of eggs laid per day as well as lifetime fecundity, which suggests that females that defer egg production to later in life lay fewer eggs, and vice versa. These results indicate a genetic tradeoff between early and late fecundity in these populations of $D$. mojavensis.

A further evaluation of the genetic tradeoff between early and late reproduction was performed by dividing total fecundity into 5-day intervals for each female and calculating correlations between all 5-day periods (Rose \& Charlesworth, 1981). Correlation analysis was only possible using sire means to estimate additive genetic correlations because individual female fecund- 

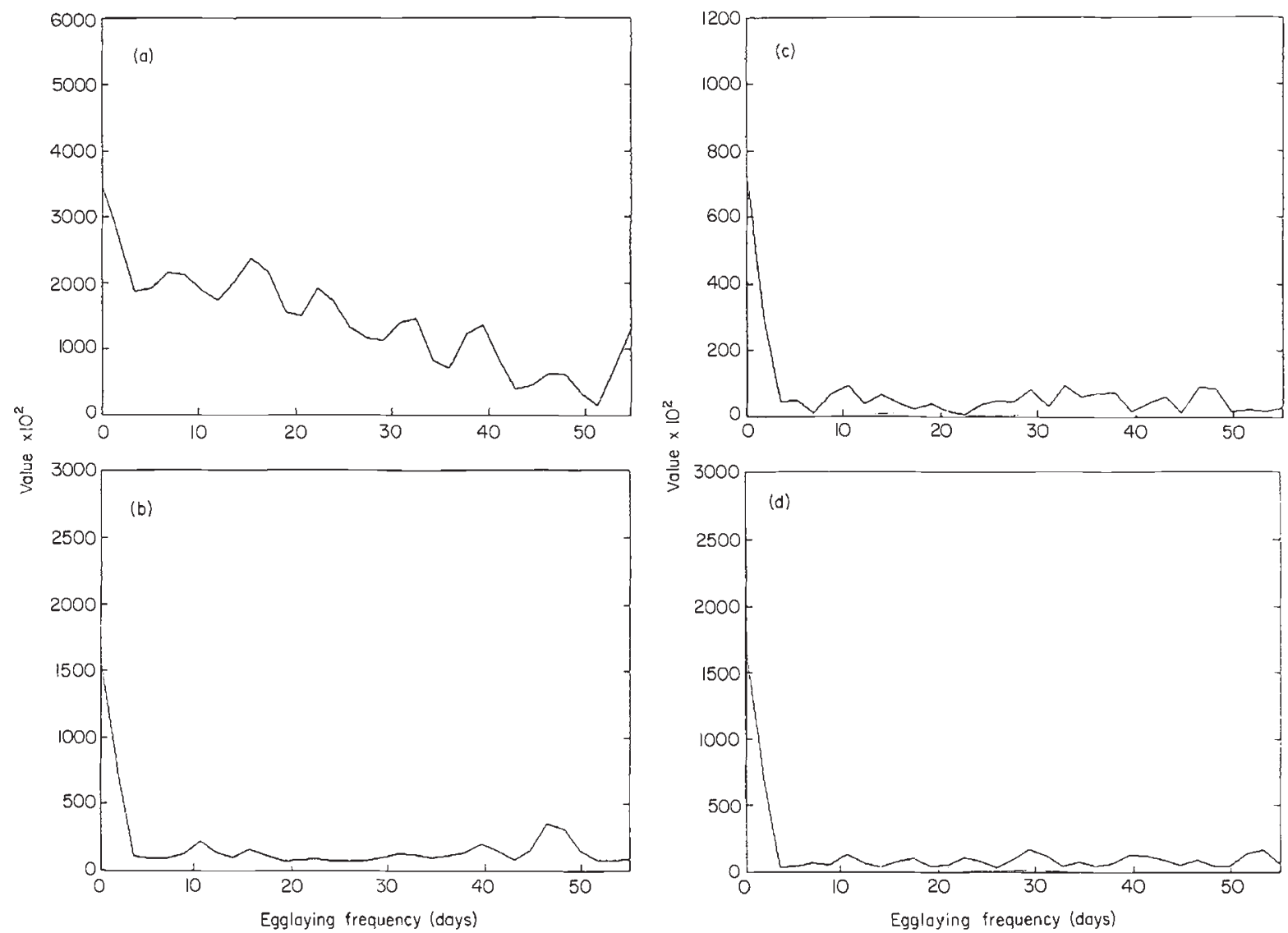

Fig. 6 Power spectra of oviposition patterns in the females from the dietary protein experiment. (a) $0 \times$ yeast, (b) $1 \times$ yeast, (c) $2 \times$ yeast, and (d) $4 \times$ yeast. See Fig. 4 and the text for details.

Table 3 Variance components (expressed as percentages of the total variance from PROC NESTED) and heritabilities of the nine fitness components in this study. Heritabilities calculated from sire variance components are 'narrow sense' heritabilities whereas the 'broad sense' heritabilities, based on dam variance components, include genotypic and maternal effects (Falconer, 1981)

\begin{tabular}{|c|c|c|c|c|}
\hline & (\%) Sire varcomp & $h^{2}$ & $(\%)$ Dam varcomp & $h^{2}$ \\
\hline Longevity & 4.404 & 0.200 & $2.448^{* *}$ & 0.111 \\
\hline Fecundity & $15.657^{* * *}$ & 0.835 & 3.102 & 0.165 \\
\hline $\begin{array}{l}\text { Number of } \\
\text { clutches laid }\end{array}$ & $14.201^{* * *}$ & 0.744 & 3.133 & 0.164 \\
\hline $\begin{array}{l}\text { Average number } \\
\text { eggs laid/day }\end{array}$ & $19.291^{* * *}$ & 1.138 & $4.304^{*}$ & 0.254 \\
\hline Clutch viability & 3.296 & 0.149 & 2.795 & 0.127 \\
\hline $\begin{array}{l}\text { Average age at } \\
\text { oviposition }\end{array}$ & $0.0 \dagger$ & 0.0 & $10.730^{* *}$ & 0.633 \\
\hline $\begin{array}{l}C V \text { of age at } \\
\text { ovipositon }\end{array}$ & 4.396 & 0.204 & 2.986 & 0.139 \\
\hline Age at peak egg lay & 2.009 & 0.131 & $12.209^{* *}$ & 0.796 \\
\hline Clutch size & 3.322 & 0.156 & 3.744 & 0.175 \\
\hline
\end{tabular}

${ }^{*} P<0.05,{ }^{* *} P<0.005,{ }^{* * *} P<0.001$.

$\dagger$ The sire variance component was negative and therefore set to zero. 
Table 4 Phenotypic correlations (top row above diagonal), genetic correlations based on sire means (second row above diagonal, $n=18$ ), additive genetic correlations (third row above diagonal), and phenotypic correlations based on the six treatment means for each population (below diagonal, $n=12$ ) for the nine life-history characters studied

\begin{tabular}{|c|c|c|c|c|c|c|c|c|c|}
\hline & LONG & FEC & CLUTCH & HATCH & AVAGE & CVAGE & PEAKAGE & EGGDAY & CLUTCHSIZE \\
\hline \multirow[t]{3}{*}{ LONG } & 1 & $0.458^{* * * *}$ & $0.418^{* * * *}$ & -0.011 & $0.548^{* * * *}$ & $0.323^{* * * *}$ & $0.464^{* * * *}$ & $0.184^{* * *}$ & $0.103 \dagger$ \\
\hline & 1 & $0.650^{* * *}$ & $0.580^{*}$ & -0.383 & -0.079 & $0.536^{* *}$ & -0.189 & $0.569^{* *}$ & $0.688^{* * *}$ \\
\hline & 1 & $0.842^{* *}$ & $0.686^{*}$ & -0.897 & 0 & 0.142 & -0.595 & $0.848^{* *}$ & 0.739 \\
\hline \multirow[t]{3}{*}{ FEC } & -0.131 & 1 & $0.889^{* * * *}$ & -0.064 & $0.428^{* * * *}$ & $0.570^{* * * * *}$ & $0.294^{* * * * *}$ & $0.889^{* * * *}$ & $0.236^{* * *}$ \\
\hline & & 1 & $0.971^{* * * *}$ & $-0.541^{* *}$ & -0.389 & $0.876^{* * * * *}$ & $-0.575^{* *}$ & $0.976^{* * * *}$ & $0.622^{* * *}$ \\
\hline & & 1 & $1.008^{* * * * *}$ & -0.660 & 0 & $0.915^{* * * *}$ & -1.825 & $1.003^{* * * *}$ & 0.190 \\
\hline \multirow[t]{3}{*}{ CLUTCH } & -0.249 & $0.954^{* * * *}$ & 1 & -0.034 & $0.425^{* * * *}$ & $0.635^{* * * *}$ & $0.206^{* * *}$ & $0.776^{* * * *}$ & $-0.157^{* *}$ \\
\hline & & & 1 & $-0.453 \dagger$ & -0.361 & $0.859^{* * * *}$ & $-0.571^{*}$ & $0.942^{* * * *}$ & $0.470^{*}$ \\
\hline & & & 1 & -0.358 & 0 & $0.797^{* * * *}$ & -1.546 & $1.012^{* * * *}$ & 0.028 \\
\hline \multirow[t]{3}{*}{ НАTCH } & -0.061 & 0.069 & 0.130 & 1 & 0.062 & $-0.105 \dagger$ & 0.089 & -0.086 & $-0.172^{*}$ \\
\hline & & & & 1 & $0.411 \dagger$ & $-0.534^{* *}$ & $0.494^{*}$ & $-0.596^{* *}$ & $-0.521^{*}$ \\
\hline & & & & 1 & 0 & -1.181 & 1.409 & $-0.916 \dagger$ & -1.651 \\
\hline \multirow[t]{3}{*}{ AVAGE } & $0.557 \dagger$ & $0.664^{* *}$ & $0.501 \dagger$ & -0.183 & 1 & $0.261^{* * * *}$ & $0.798^{* * * *}$ & $0.142^{*}$ & -0.004 \\
\hline & & & & & 1 & -0.142 & $0.941^{* * * *}$ & $-0.531^{* *}$ & -0.198 \\
\hline & & & & & 1 & 0 & 0 & 0 & 0 \\
\hline \multirow[t]{3}{*}{ CVAGE } & 0.188 & $0.539 \dagger$ & $0.502 \dagger$ & -0.323 & $0.651 \dagger$ & 1 & $0.121^{*}$ & $0.479^{* * * *}$ & $-0.155^{* *}$ \\
\hline & & & & & & 1 & -0.373 & $0.834^{* * * *}$ & $0.550^{* *}$ \\
\hline & & & & & & 1 & -3.250 & $0.932^{* * *}$ & 0.701 \\
\hline \multirow[t]{3}{*}{ PEAKAGE } & $0.608^{*}$ & 0.495 & 0.325 & -0.200 & $0.847^{* * *}$ & $0.511 \dagger$ & 1 & 0.026 & 0.075 \\
\hline & & & & & & & 1 & $-0.699^{* * *}$ & -0.287 \\
\hline & & & & & & & 1 & -2.244 & -2.140 \\
\hline \multirow[t]{3}{*}{ EGGDAY } & -0.483 & $0.898^{* * * *}$ & $0.951^{* * * *}$ & 0.178 & 0.308 & 0.341 & 0.106 & 1 & $0.305^{* * *}$ \\
\hline & & & & & & & & 1 & $0.636^{* * *}$ \\
\hline & & & & & & & & 1 & 0.273 \\
\hline CLUTCHSIZE & 0.077 & 0.183 & 0.021 & -0.091 & 0.344 & 0.203 & 0.428 & 0.028 & 1 \\
\hline
\end{tabular}

${ }^{\dagger} 0.1<P<0.05,{ }^{*} P<0.05,{ }^{* *} P<0.025,{ }^{* * *} P<0.005,{ }^{* * * *} P<0.0001$.

Adult longevity (LONG), lifetime fecundity (FEC), number of clutches laid (CLUTCH), clutch viability (HATCH), mean age of reproduction (AVAGE), coefficient of variation of the age of reproduction (CVAGE), age of largest clutch laid (PEAKAGE), mean number of eggs laid per day (EGGDAY), and clutch size (CLUTCHSIZE). Significance of additive genetic correlations was tested by calculating standard errors (Becker, 1984, p. 124) and then substituting in the formula $t=r /$ S.E. $(r)$ (Ostle \& Mensing, 1975).

ity records contained mostly zero observations due to the periodicity of oviposition and missing data due to female mortality. All but three correlations were nonsignificant, and those three were positive and showed no pattern. Nested ANOVA were performed for each interval using the same model as in Table 1 . Heritability of fecundity was only expressed in early ages, day 6-10 and $11-15$, and in the day 36-40 interval as shown by significant sire effects in the ANOVA. The significance of this pattern is again obscured by the periodicity of oviposition and attenuation of sample sizes due to female mortality.

\section{Discussion}

A significant fraction of reproductive success in female D. mojavensis is due to acquisition and assimilation of paternally contributed compounds donated during copulation. The chemical profile of these compounds is unknown, except that some are proteins (Markow \& Ankney, 1984). The effects on female survivorship and reproduction are, however, not monotonic functions of increased exposure to males (Partridge et al., 1986) and are not consistent among geographically isolated populations (Fig. 1). Intermediate exposure to males (48-96 $\mathrm{h}$ after onset of laying) produced maximum longevity but lower fecundity than any of the lifetime exposure treatments. While this pattern varied between populations, low male exposure in the 24-h treatment also decreased female longevity and fecundity. As fecundity was the lowest in this treatment, longevity decreases must result from the effects of infrequent mating, i.e. male ejaculate compounds enhanced female longevity up to a threshold past which increased egg production has antagonistic effects on longevity.

Markow (1982) determined that female $D$. mojavensis may mate with several males over a period of days, leading to sperm competition with sperm pre- 
cedence of the last mated male. Within such a mating system, it is likely that male $D$. mojavensis must remate often in order to insure that their sperm is used for fertilization and minimize the use of their ejaculates by females who have been inseminated by other males (Markow, 1988). Male fertility remains constant over as many as seven consecutive matings (Markow, 1982), while the amount of ejaculate donated drops to onethird of initial levels after the fourth mating (Markow et al., 1990). As females with continuous access to males produce more eggs than females with low male exposure, there is a direct payoff in fitness to females who remate frequently with males that do not.

Adult survivorship and reproduction in nature must therefore be influenced by at least three major factors: paternal contribution to females, nutrient availability determined by fermenting cactus tissues, and the concentration of atmospheric volatiles released during fermentation that increase adult survivorship and egg production (Etges \& Klassen, 1989). All three factors represent sources of nutrients for the yolking of eggs. An increased intake of yeasts in fermenting cactus should directly increase protein assimilation and thus cause formation of more ovarioles and larger eggs. It is widely accepted that ovarioles are formed during the pupal period from larval oogonial tissues in $D$. melanogaster (Kerkis, 1931) and that ovariole number is influenced primarily by larval nutrition (Saviliev, 1928) and genetic factors (Robertson, 1957; King, 1970). The diet-induced increase in ovarioles that we observed is the only data of which we are aware, which demonstrates an effect of adult diet on ovariole numbers, although we recognize that this intriguing result should be repeated.

The largest source of variation in nutritional quality of cactus tissues is probably the relative age of the rot, and hence the successional state of the communities of yeasts and bacteria (Fogleman \& Starmer, 1985). Larval nutrition and temperature directly influence adult body size, and therefore ovariole number and flight capability due to increases in wing size. Baja adults are genetically smaller than mainland adults and possess fewer ovarioles per female (Etges, 1990; W. B. Heed, unpublished data). It is unclear how ovarian cycling (Figs 5 and 6) influences reproductive success but it does explain why so many wild females contain few developing eggs (W. B. Heed, unpublished data): these females presumably were dissected on days immediately following oviposition. These cycles are hormone driven (Handler \& Postlethwait, 1978) and would cause increased variance in the timing of reproduction. The extent of ovarian cycling is not well known among the Drosophilidae, but several other species exhibit this behaviour, including $D$. victoria, $D$. aldrichi, D. mulleri, and D. repleta (Kambysellis, 1968). The latter three species are also cactophilic.

Life-history and mating system variation in populations of $D$. mojavensis have evolved along with colonization of alternate host cacti and increases in the geographical distribution of this species (Heed \& Mangan, 1986; Etges, 1990). Mainland and Baja populations have been classified as different subraces based upon chromosomal, allozymic, morphological, and behavioural differences (Johnson, 1980; Zouros, 1973; Zouros \& D'Entremont, 1980). Premating isolation exists between mainland and Baja populations, which suggests the formation of incipient species (Wasserman \& Koepfer, 1977; Krebs \& Markow, 1989). It has been of great interest to evaluate the determinants of these behavioural shifts, particularly with respect to differential host plant use and geographical isolation. The effects of remating frequency, a critical aspect of a group's sexual enviroment, have significantly different influences on female longevity and age-specific fecundity patterns among the populations studied (Table 1, Fig. 1). Higher levels of male exposure were required by Baja females before longevity and fecundity increased. This was probably not due to the smaller size of Baja males, and hence smaller amount of ejaculate donated, because thorax size and ejaculate volume are not correlated (Markow, et al., 1990). Mainland males do exhibit greater mating propensity than Baja males (Koepfer, 1987), which may translate into greater overall paternal contribution over the lifetime of a female.

Male effects are obviously a major component of the expression of genetic variation and covariation among traits. The heritabilities and genetic correlations reflect expression of genes underlying components of fitness across an array of mating environments, and thus may also be interpreted as genetic components of reaction norms of remating effects. Heritability of traits related to egg production traits were large compared to previous studies, but these results vary widely (Robertson, 1957; Tantawy \& El-Helw, 1966; Roff \& Mousseau, 1987). The experimental design precluded estimation of cross environment correlations which may have revealed a more detailed picture of the genetic architecture of these traits (Scheiner et al., 1991). The lack of strong evidence for a tradeoff between longevity and fecundity, due to male exposure levels, was not surprising given the non-linearity of response in longevity, and to a lesser extent fecundity (Fig. 1, Table 4). Phenotypically, age at peak reproduction was positively correlated with longevity which is consistent with a tradeoff between early and late life reproduction. However, the additive genetic correlation was negative, $r=-0.595$, indicating that females 
who laid most of their eggs early in life tended to live longer. The longevity of females was greatest in the 48 and $96 \mathrm{~h}$ exposure treatments and many of these females only laid a clutch or two early in life and did not lay again due to the absence of males (Fig. 2). Thus, males remating frequency had direct impact on the correlation structure of these traits.

Senescence resulting from antagonistic pleiotropy was evident from negative genetic correlations between the age at reproduction and peak reproduction and measures of egg production. The significance of these results to life-history theory must be tempered due to the negative correlation between clutch viability and longevity. As clutch size also increased with age, there is likely to be a physiological limit to the number of eggs a female can fertilize that is far lower than the number of eggs manufactured, even if sperm supply is unrestricted. Females can store sperm for long periods with no decrease in the viability of eggs produced (Markow, 1982). Thus, diet and ejaculate-induced increases in egg production (Figs 2 and 4) may be somewhat independent of the ability to inseminate eggs with sperm stored in the ventral recepticles, and the ability to inseminate eggs declines with age. It is unclear whether low clutch viability due to laying unfertilized eggs occurs in natural populations as well or resulted from overfeeding in the laboratory. In nature, nutrient availability may be somewhat lower and more variable, reducing the number of eggs produced to a level where females can inseminate most or all of them. Certainly, the energetic costs of producing unfertilized eggs in nutrient-limited environments would be severe. Studies of nutrient levels and associated physiological and reproductive condition of wild adults are needed before the relative significance of paternal contributions to reproductive success can be fully evaluated.

\section{Acknowledgements}

We thank C. J. Amlaner, Jr for implementing the spectral analyses with ILS, T. Dunn and J. Bly for technical assistance, R. Halliburton and G. Huckins for help in the collection of flies, $R$. Abril for performing the protein determinations, W. T. Starmer and S. Alcorn for providing the yeasts and bacteria, E. Etges and T. Martin for spiritual support, and J. Baker, S. Foster, and S. Scheiner for comments on the manuscript. This work was supported by grants NIH BRSG 2 SO7 RRO7101-12 to WJE, NSF BSR-8207056 to WBH, and the Department of Biological Sciences at the University of Arkansas.

\section{References}

ATKINSON, w. C. 1979. A comparison of the reproductive strategies of domestic species of Drosophila. J. Anim. Ecol., 48, 53-64.

BAUMANN, H. 1974 Biological effects of paragonial substances PS-1 and PS-2, in females of Drosophila funebris. J. Insect Physiol., 20, 2347-2362.

BECKER, w. A. 1984. Manual of Quantitative Genetics, Academic Enterprises, Pullman, WA.

BOGGS, C. L. 1990. A general model of the role of maledonated nutrients in female insects' reproduction. Am. Nat., 136, 598-617.

BLOOMField, P. 1976 Fourier Analysis of Time Series: An Introduction. John Wiley, New York.

BOWNES, M. AND PARTRIDGE, L. 1987 Transfer of molecules from ejaculate to females in Drosophila melanogaster and Drosophila pseudoobscura. J. Insect Physiol., 33, 941-947.

CHEN, P. S. 1984 The functional morphology and biochemistry of insect male accessory glands and their secretions. Ann. Rev. Entomol., 29, 233-255.

CHEN, P. S. AND BUHLER, R. 1970. Paragonial substance (sex peptide) and other free ninhydrin-positive components in male and female adults of Drosophila melanogaster. J. Insect Physiol., 16, 615-627.

ETGES, w. J. 1990. Direction of life history evolution in Drosophila mojavensis. In: Barker, J. S. F., Starmer, W. T. and MacIntyre, R. J. (eds) Ecological and Evolutionary Genetics of Drosophila, Plenum, New York, pp. 37-56.

ETGES, W. J. AND HEED, W. B. 1987. Sensitivity to larval density in populations of Drosophila mojavensis: Influences of host plant variation components of fitness. Oecologia, 71, 375-381.

ETGES, W. J. AND KLASSEN, C. S. 1989. Influences of atmospheric ethanol on adult Drosophila mojavensis: Altered metabolic rates and increases in fitness among populations. Physiol.Zool. 62, 170-193.

FALCONER, D. S. 1981 Introduction to Quantitative Genetics. 2nd edn, Longman, New York.

FOGLEMAN, J. C. AND STARMER, W. T. 1985. Analysis of community structure of yeasts associated with decaying stems of cactus. III. Stenocereus thurberi. Microb. Ecol., 11, 165-173.

GRANT, B. 1983. On the relationship between average copulation duration and insemination reaction in the genus Drosophila. Evolution, 37, 854-856.

GROMKO, M. H. 1987. Quantative genetic analysis of courtship and reproduction in female Drosophila melanogaster. Heredity, 62, 251-255.

GROMKO, M. н. 1989. Genetic constraint on the evolution of the courtship behavior in Drosophila melanogaster. Heredity, 58, 435-441.

HANDLER, A. M. AND POSTLETHWAIT, J. H. 1978. Regulation of vitellogenin synthesis in Drosophila by ecdysterone and juvenile hormone. J. Exp. Zool., 206, 247-254.

HEED, W. B. AND MANGAN, R. L. 1986. Community ecology of the Sonoran Desert Drosophila. In: Ashburner, M., Carson, H. L. and Thompson, J. N. Jr. (eds) The Genetics and Biology of Drosophila, Vol. 3e, Academic Press, New York, pp. 311-345.

Interactive Laboratory System. 1989. Version 6.1, Signal Technology Inc., 5951 Encina Road, Goleta, CA, 93117. 
JOHNSON, w. R. 1980. Chromosomal polymorphism in natural populations of the desert adapted species, Drosophila mojavensis. PhD Dissertation, University of Arizona.

KAMBYSELLIS, M. P. 1968. Comparative studies of oogenesis and egg morphology among species of the genus Drosophila., Univ. Tex. Publ.6818, 71-92.

KERxIS, J. 1931. The growth of the gonads in Drosophila melanogaster. Genetics, 16, 212-224.

KING, R. C. 1970. Ovarian Development in Drosophila melanogaster. Academic Press, New York.

KOEPFER, H. R. 1987. Selection for sexual isolation between geographic forms of Drosophila mojavensis. II. Effects of selection on mating preference and propensity. Evolution, 41, 1409-1412.

KREBS, R. A. AND MARKow, T. A. 1989. Courtship behavior and control of reproductive isolation in Drosophila mojavensis, Evolution, 43, 908-913.

MANE, S. D., TEPPER, C. S. AND RICHMOND, R. C. 1983. Purification and characterization of esterase 6 , a polymorphic carboxylesterase of Drosophila melanogaster. Biochem. Genet., 21, 1019-1040.

MARKow, T. A. 1982. Mating systems of cactophilic Drosophila. In Barker, J. S. F. and Starmer, W. T. (eds) Ecological Genetics and Evolution, Academic Press, New York, pp. 273-287.

MARKow, T. A. 1988. Drosophila males provide a material contribution to offspring sired by other males. Funct. Ecol., 2, 77-79.

MARKOW, T. A. AND ANKNEY, P. F. 1984. Drosophila males contribute to oogenesis in a multiply mating species. Science, 224, 302-303.

MARKOW, T. A., GALlAGHER, P. D. AND KREBS, R. A. 1990. Ejaculate-derived nutritional contribution and female reproductive success in Drosophila mojavensis (Patterson and Crow). Funct. Ecol., 4, 67-73.

MONTAGUE, J. R., MANGAN, R. L. AND STARMER, w. T. 1981. Reproductive allocation in the Hawaiian Drosophilidae: Egg size and number. Am. Nat. 118, 865-871.

ostle, B. AND MENSING, R. w. 1975. Statistics in Research, Third Edition. Iowa State University Press, Ames, IA.

PARKER, G. A. 1979. Sexual selection and sexual conflict. In: Blum, M. S. and Blum, N. A. (eds). Sexual Selection and Reproductive Competition in Insects, Academic Press, New York.

PARTRIDGE, L., GREEN, A. AND FOWLER, K. 1987. Effects of eggproduction and of exposure to males on female survival in Drosophila melanogaster. J. Insect. Physiol., 33, 745-749.

PARTRIDGE, L., FOWLER, K., TREWITT, S. AND SHARP, w. 1986. An examination of the effects of males on the survival and egg-production rates of female Drosophila melanogaster. J. Insect. Physiol., 32, 925-929.

PATTERSON, J. T. 1946. A new type of isolating mechanism in Drosophila. Proc. Nat. Acad. Sci. U.S.A., 32, 202-208.

PATTERSON, J. T. 1947. The insemination reaction and its bearing on the problem of speciation in the mulleri subgroup. Univ. Tex. Publ., 4720, 41-77.

ROBERTSON, F. W. 1957. Studies in quantitative inheritance. XI. Genetic and environmental correlation between body size and egg production in Drosophila melanogaster. J. Genet., 55, 428-443.
ROFF, D. A. AND MOUSSEAU, T. A. 1987. Quantitative genetics and fitness: lessons from Drosophila. Heredity, 58, 103-118.

ROSE, M. R. AND CHARLESWORTH, B. 1981. Genetics of life history in Drosophila melanogaster. I. Sib analysis of adult females. Genetics, 97, 173-186.

SAS INSTITUTE, INC. 1985. SAS User's Guide: Statistics, Version 5 edn. SAS Institute Inc., Cary, North Carolina.

SAVILIEV, V. 1. 1928. On the manifold effects of the gene vestigial in Drosophila melanogaster. Trav. Soc. Natural. Leningrad, 58, 65-88.

SCHEINER, S. M., CAPLAN, R. L. AND LYMAN, R. F. 1989. A search for trade-offs among life history traits in Drosophila melanogaster. Evol. Ecol. 3, 51-63.

SCHEINER, S. M., CAPLAN, R. L. AND LYMAN, R. F. 1991. The genetics of phenotypic plasticity. III. Genetic correlations and fluctuating asymmetries. J. Evol. Biol., 4, 51-68.

scotr, D. 1986. Inhibition of female Drosophila melanogaster remating by a seminal fluid (esterase 6). Evolution, 40, 1084-1091.

SONNENBLICK, B. P. 1950. The early embryology of Drosophila melanogaster. In: Demerec, M. (ed.) Biology of Drosophila, John Wiley, New York, pp. 62-167.

STARMER, W. T. 1982. Analysis of community structure of yeasts associated decaying stems of cactus. 1. Stenocereus gummosus. Microb. Ecol. , 8, 71-81.

steele, R. H. 1986a. Courtship feeding in Drosophila subobscura. I. The nutritional significance of courtship feeding. Anim. Behav., 34, 1087-1098.

STEELE, R. H. 1986b. Courtship feeding in Drosophila subobscura. II. Courtship feeding by males influences female mate choice. Anim. Behav, 34, 1099-1108.

TANTAWY, A. O. AND EL-HELW, M. R. 1966. Studies on natural populations of Drosophila. V. Correlated responses to selection in Drosophila melanogaster. Genetics, 53, 97-110.

THORNHILL, R. AND ALCOCK, J. 1983. The Evolution of Insect Mating Systems. Harvard University Press, Cambridge.

TRIVERS, R. L. 1972. Parental investment and sexual selection. In: Campbell, B. (ed.) Sexual Selection and the Descent of Man. 1871-1971. Aldine-Atherton, Chicago, pp. 136-179.

TURNER, M. E. AND ANDERSON, w. w. 1983. Multiple mating and female fitness in Drosophila pseudoobscura. Evolution, 37, 714-723.

VIA, S. 1984. The quantitative genetics of polyphagy in an insect herbivore. II. Genetic correlations in larval performance within and among host plants. Evolution, 38, 896-905.

WASSERMAN, M. AND KOEPFER, R. H. 1977. Character displacement for sexual isolation between Drosophila mojavensis and Drosophila arizonensis. Evolution, 31, 812-823.

ZEH, D. W AND SMTTH, R. L. 1985. Paternal investment by terrestrial arthropods. Am. Zool., 25, 785-805.

zouRos, E. 1973. Genic differentiation associated with the early stages of speciation in the mulleri subgroup of Drosophila. Evolution, 27, 601-621.

zouros, E. AND D'ENTREMONT, C. J. 1980. Sexual isolation among populations of Drosophila mojavensis: response to pressure from a related species. Evolution. 34, 421-430. 